International Journal of Psychological Research and Reviews (ISSN:2639-6041)

\title{
Social determinants of contraception in a context of chronic illness in hospitals in Senegal
}

\author{
Ndiaye Ndongo Ndèye Dialé, Sow Fatimata, Camara Momar, Sylla Aida, Thiam Mamadou \\ Habib
}

Service de Psychiatrie CHNU Fann, Dakar Sénégal

\begin{abstract}
Objective: We studied the socio-cultural aspects of contraception in a population of women followed for rheumatoid arthritis (RA) during the introduction of methotrexate. RA is a chronic inflammatory disease of the joints; methotrexate, its standard of care, which requires effective contraception before starting.

Patients and methods: This was a descriptive cross-sectional study that included 42 women with RA of reproductive age.

Results: The mean age of the patients was 34 years, extreme 20 and 49 years. The age group of 30-34 years was the most representative. In our study population $93 \%$ of women were married. The average duration of progression of their rheumatic disease was 60 months. Different constraints to the practice of contraception were identified: need of downstream of the spouse $(90,47 \%)$, need of downstream of the beautiful family $(23,8 \%)$, fear of the side effects $(45,23 \%)$, the desire of pregnancy for a better image in society $(14,28 \%)$.

Conclusion: several socio-cultural aspects hinder the practice of contraception in our study population. Their taking into account and a good involvement of the family is essential.
\end{abstract} ${ }^{*}$ Correspondence to Author: Ndiaye Ndongo Ndèye Dialé Service de Psychiatrie CHNU Fann,

How to cite this article: Ndiaye Ndongo Ndèye Dialé, Sow

Fatimata, Camara Momar, Sylla Aida, Thiam Mamadou Habib. Social determinants of contraception in a context of chronic illness in hospitals in Senegal. International Journal of Psychological Research and Reviews, 2019, 2:10

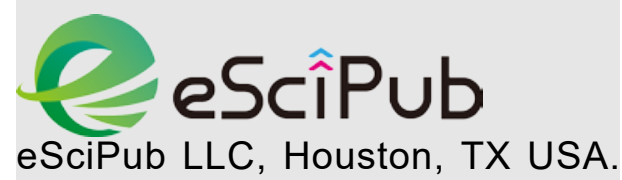
Website: http://escipub.com/

Keywords : social determinants, psychosocial,chronic illness, Senegal 


\section{Introduction}

In some societies, fertility is a symbol of social success for women, their husbands and in-laws. The context of polygamy in some households, some women at the risk of putting their lives at risk, may refuse to adhere to contraception even in chronic disease contexts.

We studied the socio-cultural aspects of contraception in a population of women followed for rheumatoid arthritis (RA) when introducing methotrexate. Rheumatoid arthritis is a chronic rheumatic disease that can affect the functional and vital prognosis. Methotrexate is one of its reference treatments, contraindicated in pregnant women because of its teratogenic effect $[1 ; 2]$. The introduction of effective contraception in women of childbearing age is essential before its introduction.

\section{Patients and methods}

This was a descriptive cross-sectional study that included women with RA. Included were those who were of childbearing age; in whom the diagnosis of RA was confirmed by a rheumatologist; and who had agreed to submit to our investigation.
The data collected included: the marital status and the various constraints noted when proposing contraception.

\section{Results}

The study included 42 women with an average age of 34 years [20 years - 49 years]. The 30-34 age group was the most represented (Figure 1). Ninety-three percent of the women were married. The study population consisted mainly of housewives with a percentage of $76 \%$, followed by shopkeepers (4\%).

At the gyneco-obstetrical level, 38 patients were followed up: $92 \%$ were followed by a midwife, $11 \%$ by a gynecologist and $5 \%$ by a general practitioner. Median pregnancy was $3[0 ; 8]$ and the median parity of $1[0 ; 7]$. Twenty patients, $48 \%$ conceived since the beginning of their PR.

Before the introduction of methotrexate, $57 \%$ of patients felt that they had been well informed about the need for contraception. Fourteen percent did not really understand why this contraception should be introduced.

Several constraints for the practice of contraception have been noted (Table I).

\section{Current age in 5-year increments}

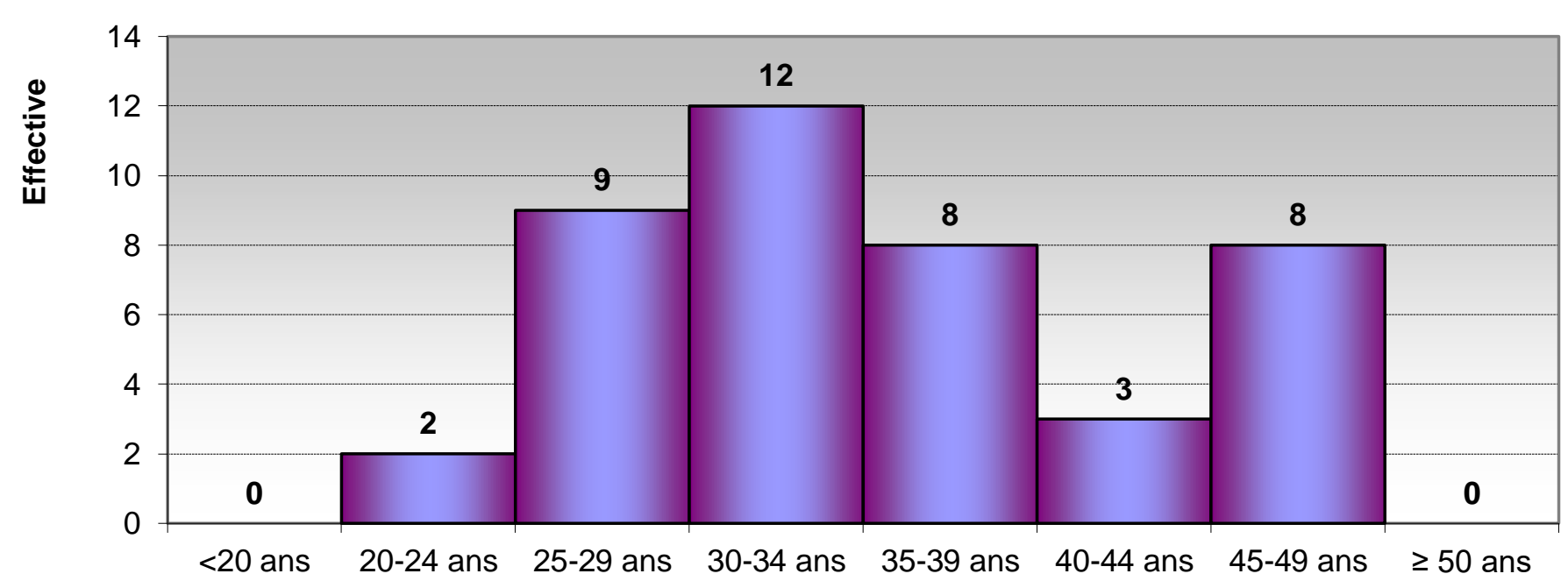


Table I: Description of constraints for the practice of contraception

Type of constraint

Need for spousal endorsement

Need downline of in-laws

Religious or mystical beliefs

Fear of permanent loss of fertility

Fear of occurrence of abdominopelvic pain

Risk of irregular bleeding

Weight gain

Current desire for pregnancy

Fear of having another pathology
Number

$38(90 \%)$

$10(24 \%)$

$1(2 \%)$

$12(29 \%)$

$7(17 \%)$

$10(24 \%)$

$2(5 \%)$

$6(14 \%)$

$7(17 \%)$

\section{Discussion}

The average age of our patients was 34 years with a strong representation of age group 30 to 40 years. It is lower than other studies in Africa where the average age of RA is between the 4th and 5th decades and in Europe where it is between the 5th and 6th decades [4]. This could be explained by our study population that included only women in genital activity. The prevalence of urban patients has also been noted in other studies in the subregion; whereas $\mathrm{RA}$ is rare in rural areas $[5 ; 6]$.

The majority of gynecological follow-up of patients was performed by midwives at $92 \%$ versus $11 \%$ of gynecologists; this fact may result from the lack of specialist doctors in Senegal.

Regarding the introduction of contraception before the start of methotrexate, $55 \%$ of patients adhered to it with a high propensity for injectable forms followed by the pill; without a statistically significant difference between the contraceptive method and the living environment. These results are superimposable with those obtained in the subregion [7] and by Floréa et al [8]. This preference for injectables could be explained by better compliance and less use constraints [9].

As for the side effects experienced or from rumors, they were mentioned as a constraint in $45 \%$. In France $33 \%$ had stopped the pill because of side effects [10]. The return to fertility was the most feared side effect. The rate of irregular bleeding found in our study (24\%) was close to $23 \%$ found by Laveissière et al. Abdominal pain is reported in 17\%; weight gain in about $5 \%$ while it was $53 \%$ in France [10]. Long-term corticosteroid therapy and inflammatory process stabilization may play an additional role in this weight gain.

Nulligestity, the desire for pregnancy and the fear of other pathologies are the other 
constraints found in our study. These could be due to false rumors, but also to the lack of adequate information on contraceptive methods.

Spousal endorsement was the most common constraint; essential for $90 \%$ of our patients with $\mathrm{p}=0.22$. In Tunisia, contraception was significantly associated with spousal approval [11]. The central place of the household and the family in our African societies, makes it difficult for a woman to join contraception without the approval of her spouse. In Senegal, the husband has a lot of power over his wife.

As Fatou Bintou Dial says, a woman is "everywhere and always subordinate to a man" when she is a daughter, mother and wife. They must obey the husband, as well as the parents of the latter because their non-obedience can lead to a divorce. The woman is completely under her control because of age difference, or financial dependence. Despite their participation in the marriage economy, their status has not changed [12]. This may explain the value accorded to their agreement on a decision as important as contraception, even in the context of a chronic condition.

The approval of the in-laws was also cited in $24 \%$. The woman must also obey the beautiful family. In Senegal, when we get married, we marry the whole family. Parents can choose the spouse and when they do not do so their consent is very important. They have the right to look at the experiences of couples and the evolution of the couple [12].

Other authors have shown how important it is for women to become mothers.

According to Lecarme, the desire for pregnancy is strongly encouraged socially and it is linked to the social success for the Senegalese woman: "The status of wife and fertile woman remains enviable and sought after: the valorization of women always goes through marriage and marriage. fertility. [13]

In addition, there is sometimes the context of polygamy, which means that they may be in competition over the number of children.

\section{Conclusion}

The study revealed a number of constraints and limits that constitute barriers to the introduction of contraception.

Certain constraints were the result of rumors, sometimes unfounded, but also of the lack of adequate information which constitutes a considerable and avoidable limit. This could be curbed by popularization and awareness policies for just and adequate information.

Thus, the endorsement of the spouse and, to a lesser extent, that of the in-laws has a major role in relation to adherence to contraception. This should lead specialists to more involvement of spouses in the follow-up of women with RA.

\section{References}

1. Adam MP, Manning MA, Beck AE et al Methotrexate/ misoprostol embryopathy: report of four cases resulting from failed medical abortion. Am J Med Genet 2003; 123: 72-8.

2. Elisabeth Elefant, Marie Pierre Cournot, Delphine Beghin et al Médicament et grossesse en rhumatologie. Rev Rhum $2010 ; 77$ : 506-10

3. Arnette FC, Edworthy SM, Bloch DA et al. The American Association 1987 revised criteria for the classification of the rheumatoid arthritis. Arthritis Rheum 1988; 31: 315-324.

4. Ndongo S, Pouye A, Ndao A.C et Al Aspects généraux de la polyarthrite rhumatoïde dans une population noire africaine: étude de 308 observations au sénégal. Rev Med Int 2011 ; 32 : P S292.

5. Mijiywa M Aspects épidémiologiques et sémiologiques de la polyarthrite rhumatoïde dans le tiers monde. Rev Rhum 1995 ; 62 : 127-32.

6. Solomon L, Robin G, Walkenburg HA Rhumatoid arthritis in an urban south African negro population. Ann Rheum Dis 1975; 34: 128-35.

7. Moutandou G, Wantou $T$ Comportement contraceptive des gabonnaises. Les méthodes modernes: Faibles taux d'utilisation et déficit d'information. Médecine d'Afrique Noire 2008 ; 48(5) : p19

8. Floréa A, Deslandre CJ Polyarthrite rhumatoïde et grossesse. Presse Med 2008 ; 37 : 1644-51.

9. Schenk DK Emergency contraception: lessons from the UK. J Fam Planning Reproduction health Care 2003; 29: 35-40.

10. Laveissière MN, Pélissier C, Lêla MG La contraception orale en France en 2001 : Résultats d'une enquête par sondage portant sur 3609 
femmes en âge de 15 à 45ans. Gynécologie Obstétrique et Fertilité $2003 ; 31: 220-9$.

11. Bouanene I, Mhamdi SE, Soltani $M$ et Al Prévalence et facteurs associés à la pratique contraceptive chez les femmes de Monastir Tunisie. Rev epid et de santé Pub 2012; 60 : p132-3.

12. Dial, F. B. (2007). Le divorce, une source d émancipation pour les femmes? Une enquête à Dakar et Saint- Louis. In T. Locoh. Genre et sociétés en Afrique : implications pour le développement (pp ). Paris : INED.

13. Lecarme-Frassy, M. (2000). Marchandes dakaroises entre maison et marché. Approche anthropologique. Paris : I Harmattan.

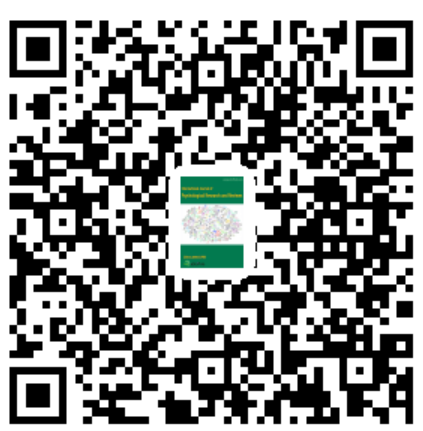

